\title{
Searching for anti-glioma activity. Ribonucleoside analogues with modifications in nucleobase and sugar moieties
}

\author{
Grzegorz Framski, Dariusz Wawrzyniak, Zofia Jahnz-Wechmann, Agnieszka Szymanska- \\ Michalak, Adam Kraszewski ${ }^{\bowtie}$, Jan Barciszewski, Jerzy Boryski and Jacek Stawinski ${ }^{凶}$ \\ Institute of Bioorganic Chemistry, Polish Academy of Sciences, Poznań, Poland
}

\begin{abstract}
Several ribonucleoside analogues with modifications in the nucleobase and sugar moiety have been screened for anti-glioma activity in the T98G glioma cell line using cervical (HeLa) cell line as reference human malignant cells, and lung fibroblast (MCR-5) cell line as non-cancerous reference cells. Among the investigated compounds, ribonucleosides containing 6-chloropurine (3), 7-guanine (5) and a pyrrolopyrimidine (18) as nucleobases, show promising anti-glioma activity with good selectivity indices, and can be considered as lead structures for further anti-cancer studies.
\end{abstract}

Key words: ribonucleoside analogues, anti-glioblastoma activity, anticancer ribonucleotides

Received: 30 May, 2016; revised: 26 June, 2016; accepted: 07 July, 2016; available on-line: 10 November, 2016

\section{INTRODUCTION}

Glioblastoma or grade IV astrocytoma, known also as glioblastoma multiforme (GBM), belongs to the most devastating brain cancers that is characterized by high malignancy and poor clinical outcome. This cancer invades the glial cells of the brain and often is malignant by the time of diagnosis. A conventional treatment of this type of cancer involves surgical resection, followed by chemotherapy and radiation therapy (Gallego, 2015). Unfortunately, this does little to improve life expectancy since the cancer usually recurs, and the length of survival after diagnosis is typically about 12 months.

Treatment of primary brain tumors is a very difficult task for several reasons. The most important are: (i) the tumor cells are resistant to conventional anticancer therapies, (ii) the brain is particularly prone to damages imparted by such interventions, (iii) the brain has a poor capacity to repair itself from the damage inflicted by chemical or radiation therapy, and finally, (iv) many drugs cannot surmount the blood-brain barrier to reach the targeted cancerous cells (Lawson et al., 2007).

To overcome these inherent problems of the GBM anticancer therapy, alternative approaches were explored. The most prominent among them are those making use of the body's immune system to eradicate malignant cells (anticancer vaccine immunotherapies) ( $\mathrm{Xu}$ et al., 2014; Yang et al., 2006), and those based on nucleic acid technologies (Catuogno et al., 2012). Immunotherapy is appealing due to its potential of high tumor specificity, which is particularly important for brain cancers (Prins et al., 2011). Some of the anti-GBM vaccines are at present in phase III clinical trials (NTC00045968) (Xu et al., 2014). As to nucleic acids as potential therapeutics, the most promising in anti-glioma therapy is a sequencespecific inhibition of RNA expressed in tumor cells by interference RNA intervention (iRNAi) (Catuogno et al., 2012; Piwecka et al., 2011; Rolle et al., 2010). Preliminary results using this technique had shown a significant improvement in the overall survival without compromising the quality of life of the patients (Rolle et al., 2010).

Apart from these, there are numerous experimental therapies investigated that involve targeting various molecules expressed in GBM in the form of inhibitors, alkylating agents, or antibodies (Agnihotri et al., 2013; Chen et al., 2014).

As part of our interest in the development of new anticancer agents, we recently investigated various 3'-Oacyl-5-fluoro-2'-deoxyuridine derivatives as potential drugs (Szymanska-Michalak et al., 2016). Although some of them displayed higher cytotoxicity against GBM of the T98G cell line than the parent 5-fluoro-2'-deoxyuridine, their SI selectivity indices were rather poor $(<5)$. Since until now the only preferred therapy against GBM is surgery, followed by a chemistry supported radiation (notably, with temozolomide as a sensitizing agent) (Neidle \& Thurston, 2005; Stupp et al., 2005), we have been searching for compounds with increased selective toxicity that could act per se as anticancer agents against this type of brain tumor. In this paper we report our results on screening of several ribonucleoside analogues with diverse structural features as potential low molecular weight selective cytotoxic agent against GBM.

\section{MATERIALS AND METHODS}

Reagents. Adenosine (1), 6-chloro-9-( $\beta$-Dribofuranosyl)purine (3), inosine (6), and cytidine (10) were of commercial grades obtained from Sigma. Other ribonucleosides used in this study were prepared according to the published procedures. Specifically, 7-( $\beta-\mathrm{D}-$ ribofuranosyl)adenine (2) and 1-( $\beta$-D-ribofuranosyl) adenine (7) were obtained as kinetic products in the ribosylation of adenine (Framski et al., 2006); 6-methyl-9( $\beta$-D-ribofuranosyl)purine (4) and 7-( $\beta$-D-ribofuranosyl) guanine (5), via transglycosylation of inosine (Boryski, 1998) and guanosine (Boryski, 2008), respectively; 1 -( $\beta$-ribofuranosyl)indazole $(\mathbf{8})$ and 2 -( $\beta$-D-ribofuranosyl) indazole (9) via direct ribosylation of indazole (Boryski, 1995); 5-azacytidine (11), via coupling of the silylated 5 -azacytosine with peracetylated ribofuranose accord-

e-mail: jstaw@ibch.poznan.pl (JS); adam.kraszewski@ibch.poznan. pl (AK)

Abbreviations: GMB, glioblastoma multiforme; MRC-5, lung fibroblast cell; T98G, glioblastoma cell line 
ing to the Vorbrüggen method (Vorbrüggen \& Bennua, 1978); 1-( $\beta$-D-ribofuranosyl)cyanuric acid (12), from silylated cyanuric acid and 1-O-acetyl-2,3,5-tri-O-benzoylD-ribofuranose (Khaled et al., 2004); 6-methyluridine (13), by Lewis acid catalyzed condensation of a silylated 6-methyl-4-methylthiouracyl with suitably protected ribofuranose (Felczak et al., 1996); 2'-C- $\beta$-methyl-D-cytidine (14), 5-aza-2'-C- $\beta$-methyl-D-cytidine (15), 5-fluoro-2'-C$\beta$-methyl-D-cytidine (16), and 2'-C- $\beta$-methyl-D-guanosine (17), were obtained by ribosylation of cytosine, its analogues, or guanine with 1,2,3,5-tetra-O-benzoyl-2'-Cmethyl- $\beta$-D-ribofuranose (Fogt et al., 2008). The series of furano[2,3-d]pyrimidine ribonucleoside derivatives (18, 19, and 20) were synthesized by the Pd-catalyzed crosscoupling of 5-iodouridine with appropriate alkyne derivatives (Jahnz-Wechmann et al., 2015; McGuigan et al., 2001; Tolstikov et al., 1993), and the pyrollo[2,3-d]pyrimidine ribonucleoside derivatives (21-26), by the ammonia treatment of the corresponding furanopyrimidine nucleoside precursors (Diez-Torrubia et al., 2011; Januszczyk et al., 2009)

Biological assays. Cell line and culture conditions. Glioblastoma cell line (T98G), cervical cancer cell line (HeLa), and non-cancerous lung fibroblast cell line (MRC-5), were purchased from ATCC (Manassas, USA). All cell lines were of human origin. HeLa were cultured in RPMI 1640 medium, and T98G as well as MRC-5, were cultured in EMEM medium. Each medium was supplemented with 10\% (v/v) foetal bovine serum (FBS) and $10 \mathrm{mg} / \mathrm{mL}$ antibiotics (penicillin and streptomycin). Cells were cultured at $37^{\circ} \mathrm{C}$ with $5 \% \mathrm{CO}_{2}$ in humidified air. Cell media (RPMI 1640 and EMEM) were obtained from Sigma-Aldrich Chemie GmbH (Steinheim, Germany) and ATCC. Cell concentrations in the culture were adjusted to allow for an exponential growth.

Cell viability/proliferation assays. The assays were performed essentially as described in our recent paper (Szymanska-Michalak et al., 2016). Cell viability/proliferation was evaluated by a dye staining method using 3-(4,5-dimethyl-2-thiazolyl)-2,5-diphenyl-2H-tetrazolium bromide (MT'T). The protocol was adapted from methods found in the literature (Xavier et al., 2011). The monolayer cell culture was trypsinized and counted. To each well of the 96-well plate, $100 \mu \mathrm{L}$ of the diluted cell suspension $\left(1 \times 10^{4}\right.$ cells) was added. After 24 hours, when a partial monolayer was formed, $100 \mu \mathrm{L}$ of the fresh medium with different compound concentrations $(7.81,15.625,31.25,62.5,125,250,500$ and $1000 \mu \mathrm{g} /$ $\mathrm{mL}$ ) were added to the cells. After 48 hours, the supernatant was washed out and $100 \mu \mathrm{L}$ of MTT solution in the medium (final concentration $0.5 \mathrm{mg} / \mathrm{mL}$ ) were added to each well for $2 \mathrm{~h}$. After the incubation time was complete, unreacted dye was removed by aspiration. The formazan crystals were dissolved in $100 \mu \mathrm{L} /$ well DMSO and measured spectrophotometrically in a multi-well Synergy2 plate reader (BioTek Instruments, USA) at a test wavelength of $492 \mathrm{~nm}$ and a reference wavelength of $690 \mathrm{~nm}$. The half-maximal inhibitory concentrations $\left(\mathrm{IC}_{50}\right)$ were calculated by fitting experimental values to sigmoidal bell-shaped equation using GraphPad Prism v5.01 (GraphPad Software, Inc., USA). Results are presented as mean of at least three independent experiments.

\section{RESULTS AND DISCUSSION}

Since most studies until now show no benefit from the addition of chemotherapy in treatment of GBM
(Stupp et al., 2005), we searched for low molecular weight compounds with increased selective cytotoxicity against GBM that could constitute a lead structure for further developments. To this end we selected four groups of ribonucleoside analogues with diverse structural and conformational features, and estimated their effect on the T98G glioblastoma cell line and HeLa as standard human malignant cells. The compounds investigated were either ribonucleoside analogues with known antiviral/anticancer properties or those being subjects of recent investigations in this laboratory. As a reference of non-cancerous cells, lung fibroblast (MCR-5) cells were used.

\section{Purine nucleoside analogues}

Adenosine receptors (ARs) emerged in the last three decades as important targets for drug development (Baraldi et al., 2008). Apart from adenosine, the natural ligand for these receptors, other nucleosides, e.g. inosine, were found to be potent triggers of these receptors (Baraldi et al., 2008; Gomez and Sitkovsky, 2003). Of particular interest in the context of the present study was the finding that activation of ARs is implicated in inhibition of tumor growth both in vitro and in vivo (Merighi et al., 2003). As potential modulators of the ARs' activity, or other unknown biological targets, nine ribonucleosides with diverse purine base modifications were selected from our nucleoside library.

Anticancer drugs should not only have potent activity at low concentrations but also should exhibit a high degree of selectivity. Therefore, all studied ribonucleoside analogues were also tested for their anti-proliferative activity against non-cancerous lung fibroblasts (MRC-5). In the selection of the least toxic compounds among the most active ones, a special parameter, known as Selectivity Index (SI) was applied (Badisa et al., 2009). The in vitro selectivity index of a drug is defined as the ratio of the toxic dose to the therapeutic dose $\left(\mathrm{SI}=\mathrm{IC}_{50}\right.$ nontumor cell line $/ \mathrm{IC}_{50}$ tumor cell line) and is a selectivity indicator of the tested compounds towards tumor cells.

The screening experiments showed that that most of the investigated ribonucleoside $\mathbf{1 - 9}$, with a notable exception of 6-methyl-9-( $\beta$-D-ribofuranosyl)purine (4), were not cytotoxic against the non-cancerous MRC-5 cells (Table 1). 6-Methylpurine nucleoside 4, that is known for its potent anti-herpes simplex virus 1 activity and nonselective cytotoxicity for cancerous cells (Montgomery and Hewson, 1968; Wu et al., 2010), in our screening also displayed high toxicity against both, HeLa and T98G cell lines, with rather low selectivity indices relative to the non-cancerous cells (Table 1).

In this subgroup of the ribonucleosides investigated, a regioisomer of natural guanosine, 7-( $\beta$-D-ribofuranosyl) guanine (5), clearly stands out from the rest, with its high, selective cytotoxicity against glioblastoma $\left(\mathrm{IC}_{50}=1.6\right)$ vs HeLa $\left(\mathrm{IC}_{50}>177\right)$, and vs MCR-5 cell lines $\left(\mathrm{IC}_{50}>100\right)$. These values translated into SI of 111 for HeLa/T98G, and SI = 64 for MRC-5/glioblastoma T98G cell lines. Also, 6-chloro-9-( $\beta$-D-ribofuranosyl)purine (3) displayed some selective cytotoxicity for glioblastoma $v$ s MRC-5 cells, but the selectivity index was rather modest $(\mathrm{SI}=23)$.

\section{Pyrimidine nucleoside analogues}

The pyrimidine ring, apart from being a part of natural nucleosides, constitutes an important pharmacophore endowed with drug like properties (Radi et al., 2009), and when appended with a sugar moiety, may show a wide 
Table 1. Cytotoxic activity of selected classes of ribonucleoside analogues*

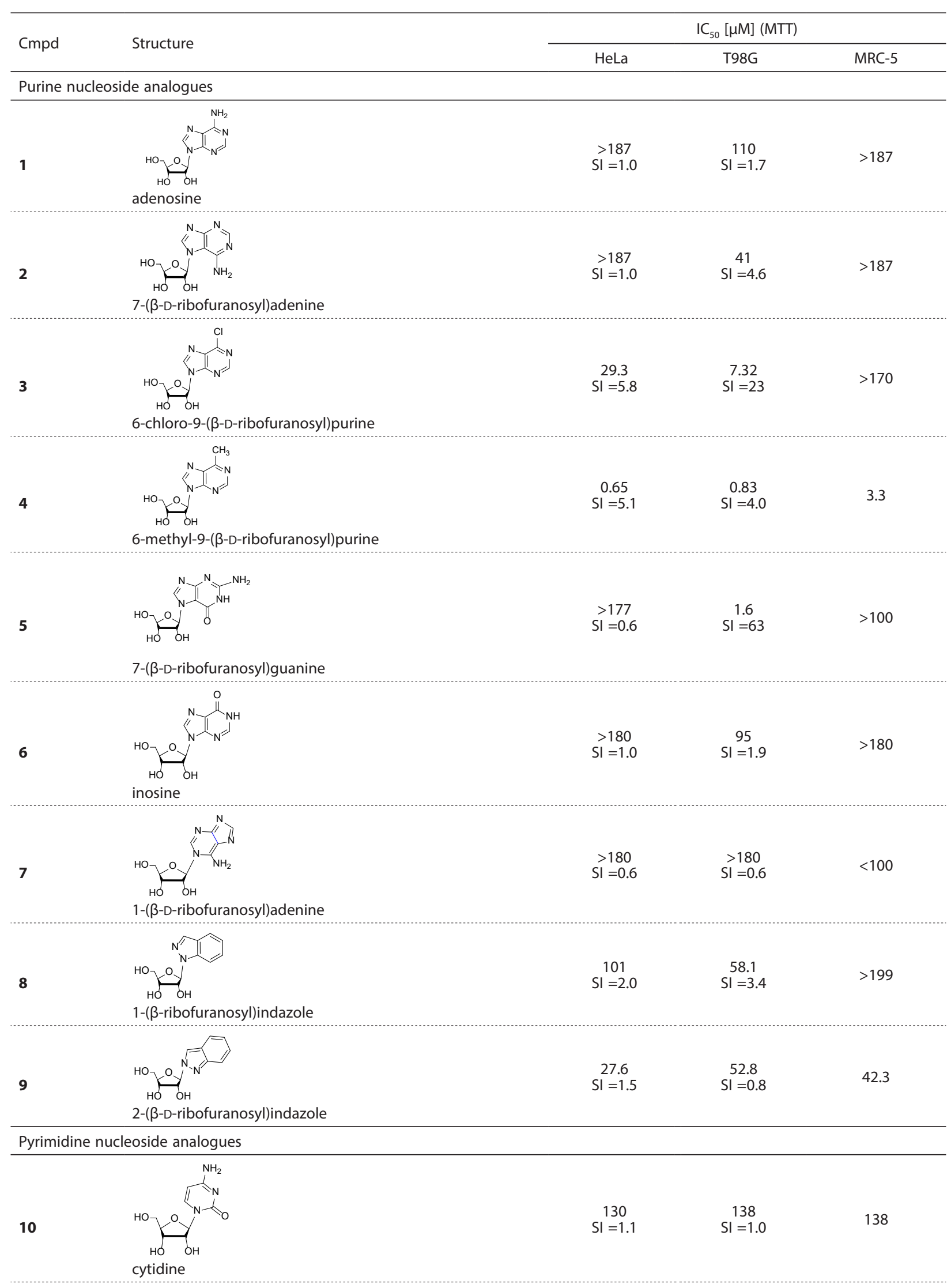


11<smiles>Nc1ncn(C2OC(O)C(O)C2O)c(=O)n1</smiles>

$\begin{array}{cc}15.89 & 12.48 \\ S I=1.4 & S I=1.8\end{array}$

5-azacytidine

OH

1-( $\beta$-D-ribofuranosyl)cyanuric acid

$\begin{array}{lcc}>191 & 48 & >191\end{array}$

12

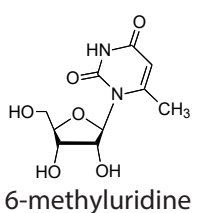

$\begin{array}{lcc}>190 & 138 & >190\end{array}$

13

6-methyluridine

Pyrimidine 2'-C-methyl nucleoside analogues

142 - $\mathrm{C}-\mathrm{\beta}$-methyl-D-cytidine

15

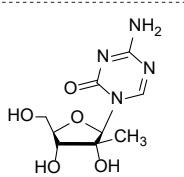$$
\text { ne }
$$

5-aza-2'-C- $\beta$-methyl-D-cytidine

16

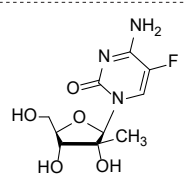$$
\mathrm{NH}_{2}
$$

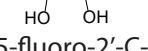

$\begin{array}{lcc}60.91 & 76.31 & 49.62 \\ \text { SI }=0.8 & \text { SI }=0.7 & \end{array}$

17

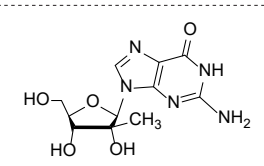

$\begin{array}{lcc}>190 & >190 & >190\end{array}$

$\mathrm{HO}$ OH
2 - $\mathrm{C}-\beta-$ methyl-D-guanosine

Pyrimidine bicyclo nucleoside analogues

18

\begin{tabular}{|c|c|c|c|}
\hline 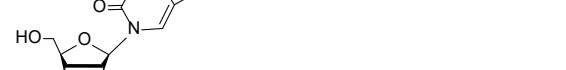 & $\begin{array}{c}17.8 \\
S I=7.3\end{array}$ & $\begin{array}{c}0.75 \\
S I=173\end{array}$ & $>130$ \\
\hline 6-octylpyrrolo[2,3-d]pyrimidine ribonucleoside & & & \\
\hline
\end{tabular}

19

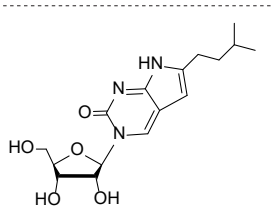

$\begin{array}{lcc}>180 & >180 & >180\end{array}$

Pyrimidine bicyclo nucleoside analogues
$>170$
$>170$
$>170$
$\mathrm{SI}=1.0$
$\mathrm{SI}=1.0$
$>170$

6-(2-methylbutyl)pyrrolo[2,3- $d$ ]pyrimidine ribonucleoside

20<smiles></smiles>

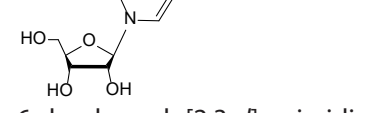

$\begin{array}{cc}18.58 & 33.07 \\ \text { SI }=1.3 & \text { SI }=0.7\end{array}$

23.64

6-decylpyrrolo[2,3-d]pyrimidine ribonucleoside 
21

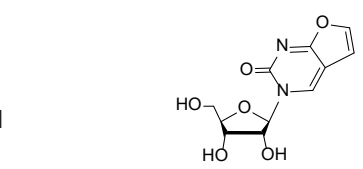

furano[2,3- $d]$ pyrimidine ribonucleoside

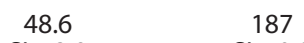

$\mathrm{SI}=2.9$
$\mathrm{SI}=0.8$

143.3

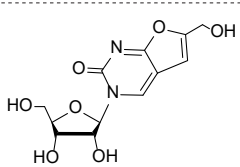

$>100$

SI $=1.0$

$>100$

$>100$

6-hydroxymethylfurano[2,3-d]pyrimidine ribonucleoside

23

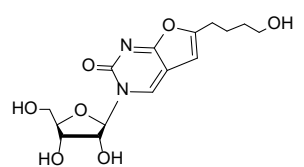

$\mathrm{OH}$

6-(1-hydroxybutylfurano[2,3-d]pyrimidine ribonucleoside

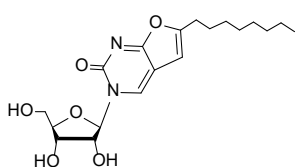

6-octyl[2,3-d]pyrimidine ribonucleoside

$$
\text { 6. }
$$

$17.15 \quad 29.71$

25

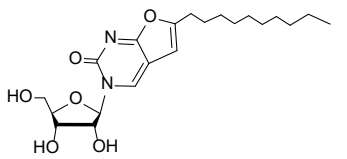

$\mathrm{SI}=1.1$

$\mathrm{SI}=0.7$

19.46

6-decyl[2,3-d]pyrimidine ribonucleoside

26

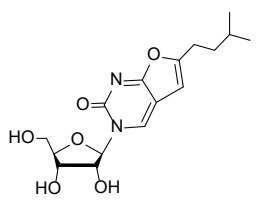

SI $=1.0$

$>100$

SI $=1.0$

$\mathrm{SI}=3.7$

74.83

6-(2-methylbutylpyrrolo[2,3-d]pyrimidine ribonucleoside

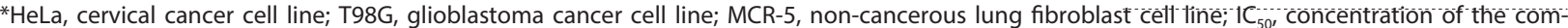
pound that inhibits cells proliferation by $50 \%$; SI, selectivity index; IC $\mathrm{C}_{50}$ non-tumor cell line/IC $\mathrm{C}_{50}$ tumor cell line.

range of pharmacological activities (Walker et al., 1979). For this study, we chose 5-azacytidine (11) and natural cytidine $(\mathbf{1 0})$ as a reference, and two ribonucleosides with a non-typical syn conformation around the glycosidic bond, namely, 1-( $\beta$-D-ribofuranosyl)cyanuric acid (12) (Khaled et al., 2004) and 6-methyluridine (13) (Felczak et al., 1996).

5-Azacytidine, which is an US FDA approved drug (Vidaza, Pharmion; inhibitor of DNA methylation) for treatment of the myelodysplastic syndrome (MDS) (Issa et al., 2005), is an analogue of cytidine in which carbon-5 in the heterocyclic ring is replaced by nitrogen. This changes the number and pattern of the hydrogen-acceptor centres when compared to cytidine 10, and may be responsible for its known general cytotoxicity. A possible role of DNA methylation in cancer therapy (Christman, 2001) prompted us to include 5-azacytidine $\mathbf{1 1}$ in our screening experiments.

Among the four investigated pyrimidine ribonucleoside analogues (Table 1 ), only 5-azacytidine 11 was cytotoxic, but with practically no selectivity against cancerous and non-cancerous cell lines. Slightly better selective toxicity against T98G was displayed by cyanuric acid nucleoside 12 , but the SI index was still low $(\mathrm{SI}=4)$.

\section{Pyrimidine 2'-C-methylnucleoside analogues}

This class of analogues retains the skeleton of natural ribonucleosides, but possesses a $\beta$-methyl substituent at the 2'-position of the D-ribose moiety. This 2'-C-methyl branching structural element (Walton et al., 1969) transforms natural ribonucleosides into potent, broad-spectrum antiviral species (Benzaria et al., 2007). For our studies, we selected 2'-C- $\beta$-methyl-D-cytidine (14), 5-aza2'-C- $\beta$-methyl-D-cytidine (15), 5-fluoro-2'-C- $\beta$-methyl-Dcytidine (16), and 2'-C- $\beta$-methyl-D-guanosine (17).

As for toxicity of the investigated compounds 14-17, only cytidine derivative 14 displayed a moderate, nonselective cytotoxicity $\left(\mathrm{IC}_{50}>50\right.$, Table 1$)$, while the rest was essentially non-toxic. From comparison with the group of pyrimidine ribonucleoside analogues (vide supra), it seems apparent that the presence of 2'-C-methyl group in the sugar moiety completely suppressed toxicity of 5-azacytidine (15 vs 11), but noticeably increased cytotoxicity of cytidine (14 vs 10).

\section{Pyrimidine bicyclo nucleoside analogues}

Addition of a furano or pyrrolo fused ring structure to pyrimidine nucleosides transformed these compounds into fluorescent, potent antiviral agents (Carangio et al., 
2001; McGuigan et al., 2001). Properties of the bicyclic, furano-pyrimidine and pyrrolo-pyrimidine, pharmacophores have been investigated mainly for deoxyribonucleoside (Carangio et al., 2001; McGuigan et al., 2001), and to lesser extent for ribonucleoside (Jahnz-Wechmann et al., 2015; Koh et al., 2007), or dideoxy derivatives (McGuigan et al., 2013).

Selected examples of this type of nucleoside analogues in our investigated series included: three lipophilic pyrrolo derivatives [6-octyl- (18), 6-(2-methylbutyl)- (19), and 6-decylpyrrolo [2,3-d]pyrimidine ribonucleosides (20)], unsubstituted furano[2,3-d]pyrimidine ribonucleoside 21, 6-hydroxymethylfurano[2,3-d]pyrimidine ribonucleoside 22, 6-(1-hydroxybutylfurano[2,3-d]pyrimidine ribonucleoside 23, and three lipophilic furano derivatives [6-octyl(24), 6-decyl- (25), and 6-(2-methylbutylpyrrolo[2,3-d]pyrimidine ribonucleosides (26)].

Although most of the investigated compounds in this subgroup were not cytotoxic or displayed a moderate to low, not selective cytotoxicity, the 6-octylpyrol derivative 18 clearly stood out with its high selective cytotoxicity against the T98G glioblastoma cells $\left(\mathrm{IC}_{50}=0.74\right)$, and high selectivity index, $\mathrm{IC}_{50} \mathrm{MRC}-5 / \mathrm{IC}_{50} \mathrm{~T} 98 \mathrm{G}, \mathrm{SI}=173$.

It seems that the pyrrolo bicyclo nucleosides in this series are on average more cytotoxic than the furano derivatives, however, a pairwise comparison, e.g. 18 vs 24, 19 vs 26, 20 vs 26, does not support this notion.

\section{CONCLUDING REMARKS}

We have screened selected compounds from our ribonucleoside library to find nucleosides with an antiglioma activity. Three of them, namely 6 -chloro-9-( $\beta$ D-ribofuranosyl)purine (3), 7-( $\beta$-D-ribofuranosyl)guanine (5), and 6-octyl-furano[2,3-d]pyrimidine ribonucleoside (18) were found to have appreciable selective cytotoxicity against T98G glioblastoma when compared to non-cancerous MRC-5 cells, and also HeLa human cancer cell line, and deserve some further studies as possible lead structures for development of an anti-glioma drug.

With the growing understanding of molecular alterations and complexity found in gliomas (Bleeker et al., 2012; Zhang et al., 2012) it seems, however, that a single-agent therapy in treatment of this kind of cancer will be insufficient; rather, a multi drug combination treatment will be necessary. This calls for further searching for anti-glioma activity in structurally diverse classes of compounds that could selectively interact with therapeutically important molecular targets revealed by the GBM cancer.

\section{Acknowledgements}

Financial support from the National Science Centre of Poland, Project No. 2011/01/B/NZ4/04936 is greatly acknowledged. Supported by the Polish Ministry of Science and Higher Education, under the KNOW program.

\section{REFERENCES}

Agnihotri S, Burrell KE, Wolf A, Jalali S, Hawkins C, Rutka JT, Zadeh G (2013) Glioblastoma, a brief review of history, molecular genetics, animal models and novel therapeutic strategies. Arch Immunol Ther Exp 61: 25-41. http://doi.org/10.1007/s00005-012-0203-0

Badisa RB, Darling-Reed SF, Joseph P, Cooperwood JS, Latinwo LM, Goodman CB (2009) Selective cytotoxic activities of two novel synthetic drugs on human breast carcinoma MCF-7 cells. Anticancer Research 29: 2993-2996. PMID: 19661306

Baraldi PG, Tabrizi MA, Gessi S, Borea PA (2008) Adenosine receptor antagonists: translating medicinal chemistry and pharmacology into clinical utility. Chem Rev 108: 238-263. http://doi.org/10.1021/ cr0682195

Benzaria S, Bardiot D, Bouisset T, Counor C, Rabeson C, Pierra C, Storer R, Loi AG, Cadeddu A, Mura M, Musiu C, Liuzzi M, Loddo R, Bergelson S, Bichko V, Bridges E, Cretton-Scott E, Mao J, Sommadossi J-P, Seifer M, Standring D, Tausek M, Gosselin G, La Colla P (2007) 2'-C-Methyl branched pyrimidine ribonucleoside analogues: potent inhibitors of RNA virus replication. Antiviral Chem Chemother 18: 225-242. PMID: 17907380

Bleeker FE, Molenaar RJ, Leenstra S (2012) Recent advances in the molecular understanding of glioblastoma. J Neurooncol 108: 11-27. http://doi.org/10.1007/s11060-011-0793-0

Boryski J (1995) Transglycosylation of $\beta$-D-Ribofuranosylindazoles. Nucleosides and Nucleotides 14: 77-89. http://doi.org/10.1080/15257779508014654

Boryski J (1998) A Novel approach to synthesis of 2'-deoxy- $\beta$-Dribonucleosedes via transglycosylation of 6-oxopurine ribonucleosides. Nucleosides and Nucleotides 17: 1547-1556. http://doi. org $/ 10.1080 / 07328319808004685$

Boryski J (2008) Reactions of transglycosylation in the nucleoside chemistry. Curr Org Chem 12: 309-325. http://doi. org/10.2174/138527208783743723

Carangio A, McGuigan C, Andrei G, Snoeck R, De Clercq E, Balzarini J (2001) Bicyclic nucleoside inhibitors of varicella-zoster virus (VZV): Pd-catalysed synthesis of 5-aryl derivatives and their biological evaluation. Antiviral Chem Chemother 12: 187-197. PMID: 12959327

Catuogno S, Esposito CL, Quintavalle C, Condorelli G, de Franciscis V, Cerchia L (2012) Nucleic acids in human glioma treatment: innovative approaches and recent results. J Signal Transduct 2012: 735135. http://doi.org/10.1155/2012/735135

Chen BJ, Wu YL, Tanaka Y, Zhang W (2014) Small molecules targeting c-Myc oncogene: promising anti-cancer therapeutics. Int $J$ Biol Sci 10: 1084-1096. http://doi.org/10.7150/ijbs.10190

Christman JK (2001) 5-Azacytidine and 5-aza-2'-deoxycytidine as inhibitors of DNA methylation: mechanistic studies and their implications for cancer therapy. Oncogene 21: 5483-5495. http://doi. org/10.1038/sj.onc

Diez-Torrubia A, Balzarini J, Andrei G, Snoeck R, De Meester I, Camarasa MJ, Velazquez S (2011) Dipeptidyl peptidase IV dependent water-soluble prodrugs of highly lipophilic bicyclic nucleoside analogues. J Med Chem 54: 1927-1942. http://doi.org/10.1021/ im101624e

Felczak K, Drabikowska AK, Vilpo JA, Kulikowski T, Shugar D (1996) 6-Substituted and 5,6-disubstituted derivatives of uridine: stereoselective synthesis, interaction with uridine phosphorylase, and in vitro antitumor activity. J Med Chem 39: 1720-1728. http://doi. org/10.1021/jm950675q

Fogt J, Januszczyk P, Framski G, Onishi T, Izawa K, De Clercq E, Neyts J, Boryski J (2008) Synthesis and antiviral activity of novel derivatives of 2'-beta-C-methylcytidine. Nucleic Acids Sym Ser 52: 605-606. http://doi.org/10.1093/nass/nrn306

Framski G, Gdaniec Z, Gdaniec M, Boryski J (2006) A reinvestigated mechanism of ribosylation of adenine under silylating conditions. Tetrabedron 62: 10123-10129. http://doi.org/10.1016/j. tet.2006.08.046

Gallego O (2015) Nonsurgical treatment of recurrent glioblastoma. Curr Oncol 22: e273-281. http://doi.org/10.3747/co.22.2436

Gomez G, Sitkovsky MV (2003) Differential requirement for A2a and A3 adenosine receptors for the protective effect of inosine in vivo. Blood 102: 4472-4478. http://doi.org/10.1182/blood-2002-11-3624

Issa JP, Kantarjian HM, Kirkpatrick P (2005) Azacitidine. Nature Rev Drug Discov 4: 275-276. http://doi.org/10.1038/nrd1698

Jahnz-Wechmann Z, Framski G, Januszczyk P, Boryski J (2015) Bioactive fused heterocycles: Nucleoside analogs with an additional ring. Eur J Med Chem 96: 388-396. http://doi.org/10.1016/j.ejmech.2014.12.026

Januszczyk P, Fogt J, Boryski J, Izawa K, Onishi T, Neyts J, De Clercq E (2009) Synthesis and antiviral evaluation of 2'-C-methyl analogues of 5-alkynyl- and 6-alkylfurano- and pyrrolo[2,3-d]pyrimidine ribonucleosides. Nucleosides Nucleotides Nucleic Acids 28: 713-723. http:// doi.org/10.1080/15257770903128870

Khaled A, Ivannikova T, Auge C (2004) Synthesis of unnatural sugar nucleotides and their evaluation as donor substrates in glycosyltransferase-catalyzed reactions. Carbohydr Res 339: 2641-2649. http://doi. org/10.1016/j.carres.2004.09.002

Koh YH, Shim JH, Girardet JL, Hong Z (2007) Design and evaluation of a potential mutagen for Hepatitis C virus. Bioorg Med Chem Lett 17: 5261-5264. http://doi.org/10.1016/j.bmcl.2007.03.091

Lawson HC, Sampath P, Bohan E, Park MC, Hussain N, Olivi A, Weingart J, Kleinberg L, Brem H (2007) Interstitial chemotherapy for malignant gliomas: the Johns Hopkins experience. $J$ Neurooncol 83: 61-70. http://doi.org/10.1007/s11060-006-9303-1

McGuigan C, Brancale A, Barucki H, Srinivasan S, Jones G, Pathirana R, Carangio A, Blewett S, Luoni G, Bidet O, Jukes A, Jarvis C, Andrei G, Snoeck R, De Clercq E, Balzarini J (2001) Furano pyrimi- 
dines as novel potent and selective anti-VZV agents. Antiviral Chem Chemother 12: 77-89. PMID: 11527045

McGuigan C, Hinsinger K, Farleigh L, Pathirana RN, Bugert JJ (2013) Novel antiviral activity of 1-dideoxy bicyclic nucleoside analogues versus vaccinia and measles viruses in vitro. J Med Chem 56: 13111322. http://doi.org/10.1021/jm301778x

Merighi S, Mirandola P, Varani K, Gessi S, Leung E, Baraldi PG, Tabrizi MA, Borea PA (2003) A glance at adenosine receptors: novel target for antitumor therapy. Pharmacol Therap 100: 31-48. http:// doi.org/10.1016/s0163-7258(03)00084-6

Montgomery JA, Hewson K (1968) Analogs of 6-Methyl-9- $\beta$ ribofuranosylpurine. J Med Chem 11: 48-52. http://doi.org/10.1021/ jm00307a010

Neidle S, Thurston DE (2005) Chemical approaches to the discovery and development of cancer therapies. Nat Rev Cancer 5: 285-296. http://doi.org/10.1038/nrc1587

Piwecka M, Rolle K, Wyszko E, Zukiel R, Nowak S, Barciszewska MZ, Barciszewski J (2011) Nucleic Acid-based Technologies in Therapy of Malignant Gliomas. Curr Pharmacet Biotech 12: 1805-1822. http:// doi.org/10.1016/j.molonc.2015.03.007

Prins RM, Soto H, Konkankit V, Odesa SK, Eskin A, Yong WH, Nelson SF, Liau LM (2011) Gene expression profile correlates with $\mathrm{T}$-cell infiltration and relative survival in glioblastoma patients vaccinated with dendritic cell immunotherapy. Clin Cancer Res 17: 16031615. http://doi.org/10.1158/1078-0432.CCR-10-2563

Radi M, Schenone S, Botta M (2009) Recent highlights in the synthesis of highly functionalized pyrimidines. Org Biomol Chem 7: 2841-2847. http://doi.org/10.1039/b906445a

Rolle K, Nowak S, Wyszko E, Nowak M, Zukiel R, Piestrzeniewicz R, Gawronska I, Barciszewska MZ, Barciszewski J (2010) Promising human brain tumors therapy with interference RNA intervention (iRNAi). Cancer Biol Therapy 9: 396-406. PMID: 20118657

Stupp R, Mason WP, van den Bent MJ, Weller M, Fisher B, Taphoorn MJB, Belanger K, Brandes AA, Marosi C, Bogdahn U, Curschmann J, Janzer RC, Ludwin SK, Gorlia T, Allgeier A, Lacombe D, Cairncross JG, Eisenhauer E, Mirimanoff RO (2005) Radiotherapy plus Concomitant and Adjuvant Temozolomide for Glioblastoma. N Engl J Med 352: 987-996. http://doi.org/10.1056/NEJMoa043330

Szymanska-Michalak A, Wawrzyniak D, Framski G, Kujda M, Zgola P, Stawinski J, Barciszewski J, Boryski J, Kraszewski A (2016)
New 3'-O-aromatic acyl-5-fluoro-2'-deoxyuridine derivatives as potential anticancer agents. Eur J Med Chem 115: 41-52. http://doi. org/10.1016/j.ejmech.2016.03.010

Tolstikov GA, Mustafin AG, Gataullin RR, Spirikhin LV, Suitanova VS, Abdrakhmanov LB (1993) New type of interaction of 5-iodopyrimidine nucleosides with alkynes. Russ Chem Bull 42: 563-598. http://doi.org/10.1007/BF00698454

Vorbrüggen H, Bennua B (1978) New Simplified Nucleoside Synthesis. Tetrahedron Lett 1339-1342. http://doi.org/10.1016/00404039(78)80123-3

Nucleoside Analogues: Chemistry, Biology, and Medical Applications (1979) Walker RT, De Clerq E, Eckstein F, eds. Plenum Press, New York, New York.

Walton E, Jenkins SR, Nutt RF, Holly FW (1969) Branched-chain sugar nucleosides. V. synthesis and antiviral properties of several branched-chain sugar nucleosides. J Med Chem 12: 306-309. http:// doi.org/10.1021/jm00302a025

Wu R, Smidansky ED, Oh HS, Takhampunya R, Padmanabhan R, Cameron CE, Peterson BR (2010) Synthesis of a 6-methyl-7-deaza analogue of adenosine that potently inhibits replication of polio and dengue viruses. J Med Chem 53: 7958-7966. http://doi.org/10.1021/ jm100593s

Xavier CP, Lima CF, Rohde M, Pereira-Wilson C (2011) Quercetin enhances 5-fluorouracil-induced apoptosis in MSI colorectal cancer cells through p53 modulation. Cancer Chemother Pharmacol 68: 1449_ 1457. http://doi.org/10.1007/s00280-011-1641-9

Xu LW, Chow KK, Lim M, Li G (2014) Current vaccine trials in glioblastoma: a review. J Immunol Res 2014: 796856. http://doi. org/10.1155/2014/796856

Yang M-Y, Zetler PM, Prins RP, Khan-Farooqi H, Liau LM (2006) Immunotherapy for patients with malignant glioma: from theoretical principles to clinical applications. Expert Rev Neurotherapeutics 6: 1481-1494. http://doi.org/10.1586/14737175.6.10.1481

Zhang X, Zhang W, Cao WD, Cheng G, Zhang YQ (2012) Glioblastoma multiforme: Molecular characterization and current treatment strategy (Review). Exp Ther Med 3: 9-14. http://doi.org/10.3892/ etm.2011.367 